\title{
Intradialytic Hypertension: Prevalence and Associated Factors in Chronic Hemodialysis Patients in Senegal
}

\author{
Faye Moustapha ${ }^{1 *}$, Lemrabott Ahmed Tall ${ }^{1}$, Kane Yaya ${ }^{2}$, Cisse Mouhamadou Moustapha1, \\ Seck Sidy Mohamed ${ }^{3}$, Faye Maria ${ }^{1}$, Daher Abdoul Karim Omar'1, Fall Khodia ${ }^{1}$, Sakho Binta1, \\ Keita Rick Alex Ismael'1, Mbengue Mansour ${ }^{1}$, Niang Abdou' ${ }^{1}$, Diouf Boucar ${ }^{1}$, Ka Elhadji Fary ${ }^{1}$ \\ ${ }^{1}$ Nephrology Department, Aristide Le Dantec Hospital, Cheikh Anta Diop University, Dakar, Senegal \\ ${ }^{2}$ Department of Nephrology, Regional Hospital Center, Assane Seck University, Ziguinchor, Senegal \\ ${ }^{3}$ Department of Nephrology, Regional Hospital Center, Gaston Berger University, Saint Louis, Senegal \\ Email: *mfayeintaida@gmail.com, mfayemed@yahoo.fr
}

How to cite this paper: Moustapha, F., Tall, L.A., Yaya, K., Moustapha, C.M., Mohamed, S.S., Maria, F., Omar, D.A.K., Khodia, F., Binta, S., Ismael, K.R.A., Mansour, M., Abdou, N., Boucar, D. and Fary, K.E. (2018) Intradialytic Hypertension: Prevalence and Associated Factors in Chronic Hemodialysis Patients in Senegal. Open Journal of Nephrology, 8, 29-37. https://doi.org/10.4236/ojneph.2018.82004

Received: April 26, 2018

Accepted: June 9, 2018

Published: June 12, 2018

Copyright $\odot 2018$ by authors and Scientific Research Publishing Inc. This work is licensed under the Creative Commons Attribution International License (CC BY 4.0).

http://creativecommons.org/licenses/by/4.0/ (c) (i) Open Access

\begin{abstract}
Introduction: Intradialytic hypertension is defined as elevation of blood pressure to more than $10 \mathrm{mmHg}$ in the post-dialysis period as compared to the pre-dialysis one. It is an important factor of morbidity and mortality in hemodialysis patients. The aim of our study is to assess the prevalence and associated factors of intradialytic hypertension. Patients and methods: This is a descriptive and analytical cross-sectional study that was conducted over a period of 3 weeks in the hemodialysis units of Aristide Le Dantec Hospital in Dakar and Regional Hospital Center in Ziguinchor. Chronic hemodialysis patients who are at least 18 years old and agreed to participate in study have been included. Patients who did not have 4 measures or those who decided to withdraw from the study were excluded. Intradialytic hypertension was restrained by an increase in systolic blood pressure immediately after the hemodialysis session $>10 \mathrm{mmHg}$ compared to that recorded before session, with a repetition of this phenomenon for at least 4 hemodialysis sessions. Results: Our study included 539 hemodialysis sessions for 93 hemodialysis patients with a mean age of $48.72 \pm 14.06$ years and a sex ratio $(\mathrm{M} / \mathrm{F})$ of 1.21 . The mean duration of dialysis was $64.22 \pm 45.63$ months. Hypertensive nephropathy was significantly common, noted in $38.7 \%$ (36 patients). Mean inter dialytic weight gain was $2.04 \pm 1.06 \mathrm{~kg}$, and the average dry weight was $62.71 \pm$ $13.69 \mathrm{~kg}$. The average hemoglobin level was $9.27 \pm 1.91 \mathrm{~g} / \mathrm{dl}$. The mean albumin level was $35.4 \pm 7.48 \mathrm{~g} / \mathrm{l}$. Nineteen (19) patients were administered erythropoietin stimulating agents $(20.4 \%)$, and 59 patients were given antihypertensive drugs (63.4\%). An elevation of more than $10 \mathrm{mmHg}$ of post-dialysis BP compared to pre-dialysis was noted in 179 sessions, which is 33.2 per 100
\end{abstract}


hemodialysis sessions. IDH was noted in 21 patients, which represents $22.6 \%$. The factors associated with IDH were as follows: high post-dialysis pulse pressure (PP) $(\mathrm{p}=0.0008)$, pre-dialysis systolic-diastolic hypertension $(\mathrm{p}=$ $0.004)$, pre-dialysis pure systolic hypertension $(\mathrm{p}=0.01)$, post-dialysis hypertension $(\mathrm{p}=0.02)$, and hypoalbuminemia $(\mathrm{p}=0.049)$. Conclusion: Although recognized for many years, the intradialytic hypertension is often neglected. However, it is common in our cohort of chronic hemodialysis with several associated factors. Its management is essential and will necessarily pass through adequate management of the blood volume.

\section{Keywords}

Intradialytic Hypertension-Hemodialysis-Senegal

\section{Introduction}

Usually, in most chronic hemodialysis patients, blood pressure (BP) decreases during the hemodialysis session due to ultrafiltration. However, in some patients, it increases and remains high during and after the dialysis session, hence the term paradoxical hypertension (HTN) [1]. Intradialytic hypertension (IDH), although discovered many years ago, is often neglected. Its definition remains imprecise and depends on the subjectivity of the authors working with it. It is most commonly defined as the elevation of BP greater than $10 \mathrm{mmHg}$ in the post-dialysis period compared to the pre-dialysis one [1]. Several pathophysiological mechanisms have been proposed to explain the genesis of IDH. Among these mechanisms, hypervolemia certainly plays a central role [2] [3] [4]. Arterial stiffness [2], the renin angiotensin aldosterone system [5], and the elimination of antihypertensive drugs through dialysis [5] are other possible pathophysiological mechanisms associated with IDH. Finally, the electrolyte imbalance [6] [7], sympathetic activity [5], use of erythropoietin stimulating agents (ESA) [8], and endothelial cell dysfunction [2] may play a role as well. IDH is commonly observed in hemodialysis patients. Recent work has focused on its clinical implications, with epidemiological evidence suggesting an association with increased morbidity and mortality [7]. Its frequency varies as per the definition used. Some data are available in the context of Africa.

To the best of our knowledge, no work has been performed evaluating IDH in a population of chronic hemodialysis in Senegal.

It is with this premise that the study was carried out, aiming to assess the prevalence of IDH in a population of chronic hemodialysis patients and to seek factors associated with it.

\section{Patients and Methods}

\subsection{Design of Study}

It was a cross-sectional and multicenter study of the descriptive and analytical 
type, which was conducted over a period of 3 weeks (from April 24, 2017 to May $12,2017)$ in the hemodialysis units of Aristide Le Dantec Hospital in Dakar and Ziguinchor Regional Hospital Center. Patients with chronic hemodialysis carried out on a regular basis ( 2 or 3 sessions per week), at least 18 years old, and those agreeing to participate in the study were included. Patients who did not have 4 measurements (measured before and after 4 hemodialysis sessions) or decided to withdraw from the study were excluded.

\subsection{Data Collection}

Data was collected utilizing a systolic BP (SBP) and diastolic BP (DBP) record card, pre- and post-dialysis for 6 hemodialysis sessions as well as an epidemiological, anthropometric, clinical data collection card, para clinical and therapeutic from patient records. These data were considered as potential associated factors with IDH.

\subsection{BP Measurement}

The BP of patients before the hemodialysis session were measured in the supine position after five minutes of rest, right before connecting the patient, and those of the end-of-session BP was measured after the extracorporeal blood circuit was restored. The measurements were carried out by dialysis technicians or nurses, using an electronic BP machine of the OMRON ${ }^{\circledR}$ and SPENGLER ${ }^{\oplus}$ type. The heart rates (HR) and weights before and after the session were also recorded. We calculated the difference between pre-dialysis and post-dialysis SBP, mean preand post-dialysis Pulse Pressure (PP), mean pre- and post-dialysis $H R$, and IDWG.

\subsection{Parameters Setting}

IDH was restrained by an increase in SBP right after the hemodialysis session by $10 \mathrm{mmHg}$ compared to that recorded before session [1], with a repetition of this phenomenon for at least 4 hemodialysis sessions [9].

\subsection{Statistical Analyses}

Data was captured utilizing the Sphinx software, version 5.1.0.2, and analyzed using SPSS (Statistical Package for Social Science), version 18. A descriptive study was performed with the calculation of frequencies and proportions for qualitative variables and calculation of the means and standard deviation for quantitative variables. An analytical study was done with crossed tables. To compare the frequencies, we applied Pearson's chi-square test or Fisher's exact two-sided test according to their applicability conditions. The comparison of averages was facilitated by the Student's t-test. The threshold of significance was retained for $\mathrm{p}$ $\leq 0.05$.

\section{Results}

During the study period, 112 out of the 114 chronic hemodialysis patients met 
the inclusion criteria, and 19 patients were later excluded. Thus, 93 patients were retained in the study, which represents $81.6 \%$ of the sample. The design of study is illustrated in Graphic 1.

The mean-age of patients was $48.72 \pm 14.06$ years and a sex ratio $(\mathrm{M} / \mathrm{F})$ of 1.21. The mean duration of dialysis was $64.22 \pm 45.63$ months. Hypertensive nephropathy was more common, noted in 36 patients, which equals $38.7 \%$, and nephropathy was indeterminate in 19 patients, which is $20.4 \%$. The mean inter dialytic weight gain (IDWG) was $2.04 \pm 1.06 \mathrm{~kg}$, and the mean dry weight was $62.71 \pm 13.69 \mathrm{~kg}$. The mean hemoglobin level was $9.27 \pm 1.91 \mathrm{~g} / \mathrm{dl}$, and the mean albumin level was $35.4 \mathrm{~g} / \mathrm{l} \pm 7.48$. Hypoalbuminemia and anemia were noted in $50 \%$ and $68.7 \%$ of patients respectively. Out of the 93 patients, $19(20 \%)$ were on ESA, $59(63.4 \%)$ were on antihypertensive treatment. The characteristics of patients are presented in Table 1 and antihypertensive drug type used is given in Table 2.

The mean pre-dialysis BP was $144.48 \pm 17.89 / 84.92 \pm 13.99 \mathrm{mmHg}$, and the post-dialysis one was $146.38 \pm 24.09 / 87.55 \pm 15.17 \mathrm{mmHg}$. The mean pre-dialysis HR was $75.86 \pm 10.9$ pulsation per minute $(\mathrm{ppm})$, and the post-dialysis HR was $77.06 \pm 12.37 \mathrm{ppm}$. The mean pre-dialysis PP was $59.6 \pm$ $16.20 \mathrm{mmHg}$, and that of the post-dialysis was $58.83 \pm 17.89 \mathrm{mmHg}$.

During the study period, the SBP of 539 hemodialysis sessions were recorded at an average of $5.8 \pm 0.5$ sessions per patient. Among these 539 sessions, an increase of more than $10 \mathrm{mmHg}$ of post-dialysis BP compared to that of pre-dialysis was observed in 179 sessions, which corresponds to 33.2 per 100 hemodialysis sessions. IDH was noted in 21 patients representing $22.6 \%$. Factors that could influence the increase in SBP during the hemodialysis session were as follows: high post-dialysis PP, pre-dialysis systolic-diastolic HTN, pure pre-dialysis systolic HTN, and hypoalbuminemia. Associated factors with IDH are shown in Table 3.

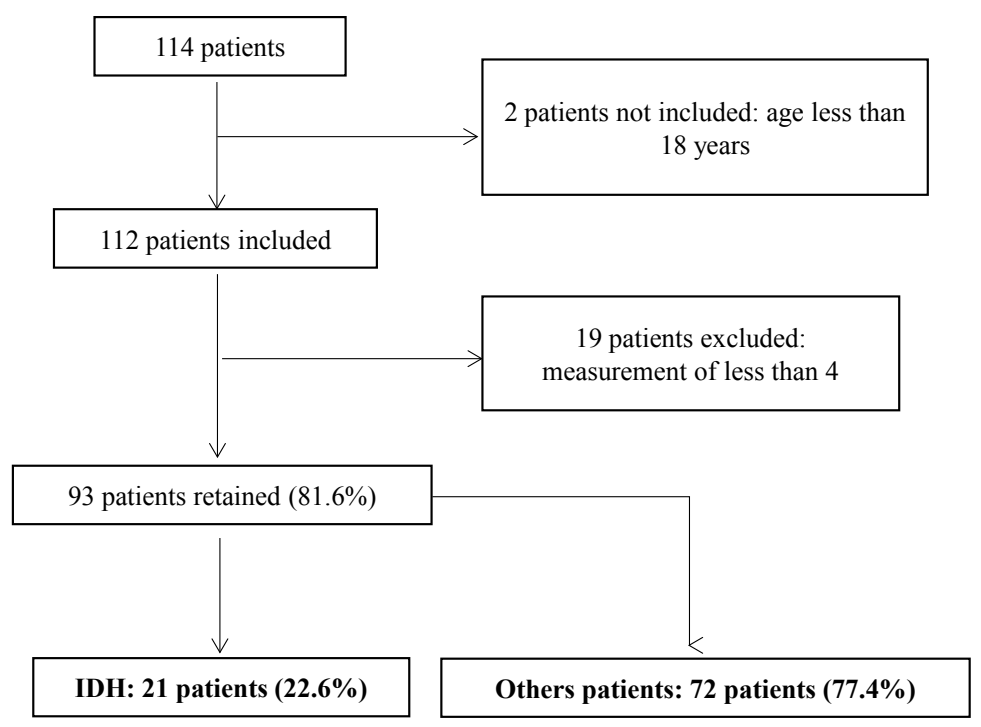

Graphic 1. Design of study. 
Table 1. Characteristics of patients.

\begin{tabular}{|c|c|c|c|}
\hline Parameters & All patients & IDH & Control \\
\hline Number & 93 & 21 & 72 \\
\hline Age (years) & $48.72 \pm 14.06$ & $49.14 \pm 13.21$ & $48.6 \pm 14.39$ \\
\hline Gender: Male & $51(54.8 \%)$ & $14(66.7 \%)$ & $37(51.4 \%)$ \\
\hline Female & $42(45.2 \%)$ & $7(33.3 \%)$ & $35(48.6 \%)$ \\
\hline Duration in dialysis (months) & $64.22 \pm 45.63$ & $51.38 \pm 39.8$ & $67.96 \pm 46.79$ \\
\hline Hypertensive nephropathy & $36(38.7 \%)$ & $11(52.4 \%)$ & $25(34.7 \%)$ \\
\hline Glomerulonephritis & $20(21.5 \%)$ & $3(14.3 \%)$ & $17(22.2 \%)$ \\
\hline Unknown Nephropathy & $19(20.4 \%)$ & $3(14.3 \%)$ & $16(22.2 \%)$ \\
\hline Dry weight (Kg) & $62.71 \pm 13.69$ & $59.19 \pm 11.26$ & $63.73 \pm 14.23$ \\
\hline IDWG (Kg) & $2.04 \pm 1.06$ & $1.86 \pm 1.22$ & $2.09 \pm 1.01$ \\
\hline Arteriovenous Fistula & $64(68.8 \%)$ & $14(66.7 \%)$ & $50(69.4 \%)$ \\
\hline Single catheter & $10(10.8 \%)$ & $2(9.5 \%)$ & $8(11.1 \%)$ \\
\hline tunneled catheter & $19(20.4 \%)$ & $5(23.8 \%)$ & $14(19.4 \%)$ \\
\hline Mean BMI $\left(\mathrm{Kg} / \mathrm{m}^{2}\right)$ & $21.36 \pm 4.26$ & $20 \pm 3.73$ & $21.72 \pm 4.34$ \\
\hline Residual Diuresis & $42(45.2 \%)$ & $11(52.4 \%)$ & $31(43.1 \%)$ \\
\hline Intradialytic hypotension & $11(11.8 \%)$ & 0 & $11(15.3 \%)$ \\
\hline Anemia & $57(68.7 \%)$ & $14(73.7 \%)$ & $43(67.2 \%)$ \\
\hline Hemoglobin (g/dl) & $9.27 \pm 1.91$ & $9.08 \pm 1.69$ & $9.33 \pm 1.98$ \\
\hline Serum albumin $(\mathrm{g} / \mathrm{l})$ & $35.4 \pm 7.48$ & $32.67 \pm 5.87$ & $36.44 \pm 7.86$ \\
\hline Hypoalbuminemia & $18(50 \%)$ & $7(33.3 \%)$ & $10(13.9 \%)$ \\
\hline Serum calcium (mg/l) & $88.71 \pm 6.18$ & $90.99 \pm 5$ & $88.07 \pm 6.37$ \\
\hline Serum phosphate (mg/l) & $36.22 \pm 12.03$ & $37.43 \pm 9.84$ & $35.9 \pm 12.6$ \\
\hline PTH (ng/l) & $745.91 \pm 593.49$ & $734.49 \pm 590.37$ & $749.18 \pm 602.92$ \\
\hline LVH (ECG) & $29(53.8 \%)$ & $5(23.8 \%)$ & $24(33.3 \%)$ \\
\hline LVH (TTE) & $7(13.2 \%)$ & $2(9.5 \%)$ & $10(13.9 \%)$ \\
\hline ESA & $19(20.4 \%)$ & $2(9.5 \%)$ & $17(23.6 \%)$ \\
\hline Iron treatment & $15(16.1 \%)$ & $2(9.5 \%)$ & $13(18.1 \%)$ \\
\hline Calcium treatment & $39(42.4 \%)$ & $7(33.3 \%)$ & $32(45.1 \%)$ \\
\hline
\end{tabular}

ECG: electrocardiogram; TTE: Transthoracic Echocardiography; LVH: Left Ventricular Hypertrophy.

Table 2. Types of antihypertensive drugs used.

\begin{tabular}{cccc}
\hline Type & $\begin{array}{c}\text { All patients } \\
(\mathrm{n}=93)\end{array}$ & IDH & Control \\
\hline Antihypertensive treatment & $59(63.4 \%)$ & $17(81 \%)$ & $42(58.3 \%)$ \\
ICE & $37(39.8 \%)$ & $10(55.6 \%)$ & $27(55.1 \%)$ \\
AAR & $7(11.3 \%)$ & $3(17.6 \%)$ & $4(8.9 \%)$ \\
ICC & $41(66.1 \%)$ & $13(76.5 \%)$ & $28(62.2 \%)$ \\
Beta-blockers & $16(25.8 \%)$ & $5(29.4 \%)$ & $11(24.4 \%)$ \\
Number of molecules (mean) & $1.98 \pm 1.06$ & $2.06 \pm 1.25$ & $1.95 \pm 0.99$ \\
\hline
\end{tabular}

ICE: Inhibitors of the Conversion Enzyme; AAR: Antagonist of Angiotensin II Receptors; ICC: Inhibitors of Calcium Channels. 
Table 3. Associated factors of IDH.

\begin{tabular}{cccc}
\hline \multirow{2}{*}{ Parameters } & \multicolumn{2}{c}{ IDH } & \multirow{2}{*}{$\mathrm{p}$} \\
\cline { 2 - 3 } & Yes $(\mathbf{n}=\mathbf{2 1})$ & Now $(\mathbf{n}=\mathbf{7 2})$ & \\
\hline PP post-dialysis (mmHg) & $70.25 \pm 15.99$ & $55.49 \pm 17.11$ & $<0.001$ \\
HTN systolic-diastolic & $11(84.6 \%)$ & $16(39 \%)$ & 0.004 \\
Pure HTN systolic & $2(15.4 \%)$ & $23(56.1 \%)$ & 0.010 \\
Hypoalbuminemia & $7(33.3 \%)$ & $10(13.9 \%)$ & 0.049 \\
HTN post-dialysis & $21(100 \%)$ & $50(69.4 \%)$ & 0.020 \\
\hline
\end{tabular}

\section{Discussion}

During the study period, 539 hemodialysis sessions were recorded. This result is lower than those of Sinomono [10] in Morocco and Attilio [11] in Italy, which respectively reported 828 and 51,504 hemodialysis sessions. This difference can be justified by the availability issues pertaining to the electronic BP machine in our services. We recorded an increase in post-dialysis SBP compared to pre-dialysis SBP in 179 hemodialysis sessions, which is 33.2 per 100 hemodialysis sessions. This prevalence was significantly higher than that reported by Van Buren in 2012, which was 21.3 per 100 hemodialysis sessions [12].

IDH is generally perceived as a rare phenomenon in hemodialysis [13] [14]. In several studies applying the same criteria, its prevalence was less than $15 \%$ [15]. In our study, we have reported a relatively significant prevalence of IDH at $22.6 \%$. This prevalence was comparable to that reported by Attilio [11] in Italy, which was $23.1 \%$. However, it was lower than that of Sinomono [10] in Morocco, Sebastian [16] in South Africa and Mackanga [17] in Gabon, which reported prevalence rates of $29.17 \%, 28.4 \%$, and $28.99 \%$ respectively. It was higher than that of the CLIMB study [18] as well asthe WAVE 2 study [19], which reported respective prevalence rates of $13.2 \%$ and $12 \%$. The noted prevalence of IDH in our study was alarming, as it is currently considered a risk factor for cardiovascular mortality [11]. Inrig et al. [20] noted an increased risk of hospitalization and death at 6 months in patients who had an increase in BP by $10 \mathrm{mmHg}$ during the hemodialysis session as compared to the patients whose BP decreased during the hemodialysis session. Post-dialysis SBP was also more significantly correlated with the ambulatory inter dialytic BP than pre-dialysis [21]. Its management is necessary and can be facilitated through the adequate management of the blood volume with the estimate of an ideal weight, individualization of hemodialysis parameters, and use of modules for retro control of ultrafiltration. It is also necessary to identify such associated factors to support them optimally.

In our study, factors that could influence the increase in SBP during the hemodialysis session were as follows: high post-dialysis PP, pre-dialysis systolic-diastolic HTN, pure pre-dialysis systolic hypertension, and hypoalbuminemia $(\mathrm{p}=0.049)$.

High PP was a predictor of IDH $(70.25 \pm 15.99$ vs $55.49 \pm 17.11)$, with a p-value at 0.0008 . This association is alarming. Several studies have shown that 
$\mathrm{PP}$ is a cardiovascular risk factor that is independent of the average arterial pressure. This risk factor primarily plays a role in the prediction of a myocardial infarction and, to a lesser degree, in the prediction of cerebrovascular accidents, where the average arterial pressure plays a greater role than pulse pressure [22]. In the Attilio study, IDH was associated with PP pre-dialysis rather than post-dialysis [11].

Pre-dialysis systolic-diastolic HTN was also an associated factor for IDH ( $\mathrm{p}=$ 0.004), whereas patients with pure systolic HTN pre-dialysis performed less better IDH (protective factor) $(\mathrm{p}=0.01)$. In the Sinomono study [10], HTN at beginning of session was considered a risk factor $(\mathrm{p}<0.001)$.

In our study, patients in the IDH group were older (IDH vs control, $49.14 \pm$ 13.21 vs $48.6 \pm 14.39)$ and presented lower mean IDWG $(1.86 \pm 1.22$ vs $2.09 \pm$ $1.01)$, lower average dry weight $(59.19 \pm 11.26 \mathrm{vs} 63.73 \pm 14.23 \mathrm{~kg})$ as well as a lower BMI $(20 \pm 3.73$ vs $21.72 \pm 4.34)$ than those in the control group, without recording a statistically significant difference.

We noted regression in the prevalence of IDH with dialysis duration and no statistically significant difference $(\mathrm{p}=0.32)$ : from 1 to 59 months $=54.8 \%$; 60 to 199 months $=32.3 \% ; 120$ to 179 months $=9.7 \%$; and 180 months and over $=$ $3.2 \%$; moreover, it was noted with the increase in IDWG: less than $2 \mathrm{~kg}=32.1 \%$ (9); from 2 to $3 \mathrm{~kg}=20 \%$ (9); and $3 \mathrm{~kg}$ and more $=15 \%$ (3).

\section{Conclusion}

IDH remains a frequent phenomenon in chronic hemodialysis patients and is often neglected. In our study, it was observed in 21 patients, which represents $22.6 \%$ of our sample. It is associated with mortality and increased morbidity, especially in terms of cardiovascular issues. High post-dialysis PP, pre-dialysis systolic-diastolic HTN, pure pre-dialysis systolic hypertension, and hypoalbuminemia were significantly associated with IDH. This must be sought and supported primarily through the adequate management of the volume and secondarily through the mastery of vasoconstriction by the individualization of dialysis and antihypertensive drugs.

\section{Limitation of the Study}

It is a cross-sectional study with para clinical data collected retrospectively. Analytically, the small number of patients does not make it possible to affirm the associations found. Other multicenter and prospective studies are needed to confirm these associations.

\section{Conflicts of Interest}

The authors declare not to have any conflict of interest in relation to this article.

\section{References}

[1] Cirit, M., Akcicek, F., Terzioglu, E., et al. (1995) "Paradoxical" Rise in Blood Pressure during Ultrafiltration in Dialysis Patients. Nephrology Dialysis Transplanta- 
tion, 10, 1417-1420.

[2] Georgianos, P.I., Sarafidis, P.A., Zoccali, C., et al. (2015) Intradialysis Hypertension in End-Stage Renal Disease Patients Clinical Epidemiology, Pathogenesis, and Treatment. Hypertension, 66, 456-463. https://doi.org/10.1161/HYPERTENSIONAHA.115.05858

[3] Van Buren, P.N. and Inrig, J.K. (2016) Mechanisms and Treatment of Intradialytic Hypertension. Blood Purification, 41, 188-193. https://doi.org/10.1159/000441313

[4] Van Buren, P.N., Zhou, Y.Y. and Javier, A. (2016) Extracellular Volume Overload and Increased Vasoconstriction in Patients with Recurrent Intradialytic Hypertension. Kidney and Blood Pressure Research, 41, 802-814. https://doi.org/10.1159/000450565

[5] Touam, M., Joly, D. and Bobrie, G. (2011) Hypertension artérielle intradialytique. In: actualités néphrologiques. Médecine sciences publications/lavoisier, 265-278.

[6] Song, Jh., Park, Gh. and Lee, Sy., et al. (2005) Effect of Sodium Balance and the Combination of Ultrafiltration Profile during Sodium Profiling Hemodialysis on the Maintenance of the Quality of Dialysis and Sodium and Fluid Balances. Journal of the American Society of Nephrology, 16, 237-246. https://doi.org/10.1681/ASN.2004070581

[7] Chou, K.J., Lee, P.T., Chen, C.L., et al. (2006) Physiological Changes during Hemodialysis in Patients with Intradialysis Hypertension. Kidney International, 69, 1833-1838. https://doi.org/10.1038/sj.ki.5000266

[8] Maschio, G. (1995) Erythropoietin and Systemic Hypertension. Nephrology Dialysis Transplantation, 10, 74-79. https://doi.org/10.1093/ndt/10.supp2.74

[9] Gunal, A.I., Karaca, I., Celiker, H., et al. (2002) Paradoxical Rise in Blood Pressure during Ultrafiltration Is Caused by Increased Cardiac Output. Journal of Nephrology, 15, 42-47

[10] Eyeni Sinomono, D.T., Dami, F., Ndiaye, A., et al. (2015) Hypertension Intradialytique: incidence et facteurs de risque. Néphrologie \& Thérapeutique, 11, 310. https://doi.org/10.1016/j.nephro.2015.07.125

[11] Losito, A., Del Vecchio, L., Del Rosso, G., et al. (2016) Postdialysis Hypertension: Associated Factors, Patient Profiles, and Cardiovascular Mortality. American Journal of Hypertension, 29, 684-689. https://doi.org/10.1093/ajh/hpv162

[12] Van Buren, P.N., Kim, C., Toto, R.D., et al. (2012) The Prevalence of Persistent Intradialytic Hypertension in a Hemodialysis Population with Extended Follow-Up. The International Journal of Artificial Organs, 35, 1031-1038. https://doi.org/10.1177/039139881203501201

[13] Chazot, C. and Jean, G. (2010) Intradialytic Hypertension: It Is Time to Act. Nephron Clinical Practice, 115, 182-188. https://doi.org/10.1159/000313031

[14] Davenport, A. (2006) Intradialytic Complications during Hemodialysis. Hemodialysis International, 10, 162-167. https://doi.org/10.1111/j.1542-4758.2006.00088.x

[15] Inrig, J.K. (2010) Intradialytic Hypertension. A Less-Recognized Cardiovascular Complication of Hemodialysis. American Journal of Kidney Diseases, 55, 580-589. https://doi.org/10.1053/j.ajkd.2009.08.013

[16] Sebastian, S., Filmalter, C., Harvey, J., et al. (2016) Intradialytic Hypertension during Chronic Haemodialysis and Subclinical Fluid Overload Assessed by Bioimpedance Spectroscopy. Clinical Kidney Journal, 9, 636-643. https://doi.org/10.1093/ckj/sfw052 
[17] Mackanga, J.R., Oliveira, G., Ehoumba, F., et al. (2016) Variation paradoxale de la pression artérielle systolique en fin de dialyse: Prévalence et facteurs associés. Neph \& Ther, 12, 294. https://doi.org/10.1016/j.nephro.2016.07.018

[18] Reddan, D.N., Szczech, L., Hasselblad, V., et al. (2005) Intradialytic Blood Volume Monitoring in Ambulatory Hemodialysis Patients: A Randomized Trial. Journal of the American Society of Nephrology, 16, 2162-2169.

https://doi.org/10.1681/ASN.2004121053

[19] Inrig, J.K., Patel, U.D., Toto, R.D., et al. (2009) Association of Blood Pressure Increases during Hemodialysis with 2-Year Mortality in Incident Hemodialysis Patients: A Secondary Analysis of the Dialysis Morbidity and Mortality Wave 2 Study. American Journal of Kidney Diseases, 54, 881-890.

https://doi.org/10.1053/j.ajkd.2009.05.012

[20] Inrig, J.K., Oddone, E.Z., Hasselblad, V., et al. (2007) Association of Intradialytic Blood Pressure Changes with Hospitalization and Mortality Rates in Prevalent ESRD Patients. Kidney International, 71, 454-461.

https://doi.org/10.1038/sj.ki.5002077

[21] Van Buren, P.N., Kim, C., Toto, R., et al. (2011) Intradialytic Hypertension and the Association with Interdialytic Ambulatory Blood Pressure. Clinical Journal of the American Society of Nephrology, 6, 1684-1691.

https://doi.org/10.2215/CJN.11041210

[22] Hassan, B., Ezzouak, A., Badidi, M., et al. (2014) La pression pulsée et le risque cardiovasculaire: A propos de 700 sujets hypertendus. Research fr 1, 1038. 